\title{
The gem-dimethyl effect in reactions through tetrahedral intermediates: cyclizations of some ethyl 2,3-disubstituted-5-(p- nitrophenyl) hydantoates
}

\author{
Asen H. Koedjikov, Petko M. Ivanov, and Ivan G. Pojarlieff* \\ Institute of Organic Chemistry, Bulgarian Academy of Sciences, ul. Acad. G. Bonchev block 9, \\ Sofia 1113, Bulgaria \\ E-mail: ipojarli@orgchm.bas.bg
}

Dedicated to Professor Oswald Tee on the occasion of his $60^{\text {th }}$ birthday (received 13 Sep 01; accepted 25 Oct 01; published on the web 02 Nov 01)

\begin{abstract}
The kinetics of cyclization for 3-ethyl-, 3-isopropyl-and 3-hexyl-substituted hydantoates 2-UE to the corresponding hydantoins $\mathbf{2 - H y d}$ were studied in an attempt to examine the gem-dimethyl effect (GDME) in a case where the tetrahedral center of the intermediate $\mathbf{T}$ is not fully screened. However, in these congested compounds, the increase in strain in the open chains paralleled that of the intermediates resulting in meager rate enhancements - an interpretation confirmed by MM3 calculations. In the case of the largest substituent 2d-UE a new reaction appeared in the rate profile, together with substantial changes concerning the points of transition from r.d. formation to breakdown of $\mathbf{T}$ in the $\mathrm{OH}^{-}$and general base catalysis. All these agree with the concept that the GDME tends to shift the transition state to an earlier step of the cyclization reaction.
\end{abstract}

Keywords: Hydantoates, cycliczations, tetrahedral intermediates, gem-dimethyl effect

\section{Introduction}

The gem-dimethyl effect ${ }^{1}$, GDME, i.e. the acceleration of cyclization reactions by substituents in the chain, is a convenient means of designing bioorganic substrates because of the expected minor perturbations in reactivity. Sometimes, however, substituents may slow down the reaction instead of making it faster and worse, as far as models are concerned, cause a change in mechanism. Often the reasons for the retardation are trivial and can be traced to steric hindrance. Recently, we observed ${ }^{2,3}$ loss of the GDME in the base-catalyzed cyclization of ethyl hydantoates when all hydrogens are replaced by methyl groups accompanied by a change in the mechanism. The role of steric repulsions in the tetrahedral intermediate was excluded because the acid-catalyzed cyclization showed a normal GDME. The case of ethyl 5-(p-nitrophenyl)- 
hydantoates (UE) was particularly intriguing since these compounds exhibited complex pH-rate profiles and that of the trimethylated ester 3-UE was distinctly different showing a loss of the GDME for $\mathrm{OH}^{-}$catalysis and changes in mechanism both for acid and for base catalysis. The variation in rate and mechanism with the introduction of methyl groups in the chain could be explained by the interplay of two factors:

(a) The GDME eases cyclization but hinders ring-opening. This results from strain in the open compound being relieved in the ring because the bonds forming the cycle are forced into unfavourable conformations thus leaving more freedom for the substituents. In cyclizations through tetrahedral intermediates ${ }^{4}$ giving rigid products such as hydantoins flexibility is gradually lost along the reaction path and the GMDE will influence both steps of Scheme 1. If $k_{f 2}$ is rate determining the GDME can shift the overall transition state towards the first stage, $k_{f 1}$, by making $k_{r 1}<k_{f 2}$.

(b) Steric hindrance to proton transfer to the departing ethoxy anion in the permethylated intermediate $\mathbf{3}-\mathbf{T}^{-}$which contrarily makes the second stage, $k_{f 2}$, slow in the base-catalyzed reaction. The latter hindrance arises in the ring intermediate because the oxygen atom of the ethoxy group is flanked by the gem-dimethyl group on one side and the substituent $\mathrm{R}^{3}$ on $1-\mathrm{N}$ on the other while a frontal approach is made difficult by the ethyl group. In the 5-(pnitrophenyl)hydantoates ${ }^{2}$ and related cases ${ }^{3}$ the change in mechanism is accompanied by a loss of the GDME because the proton transfer step has become more slow than the cyclization step forming $\mathbf{T}^{-}$.

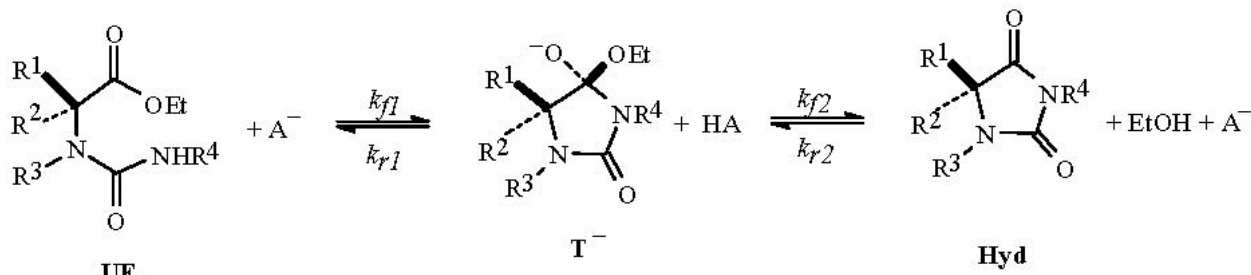

UE

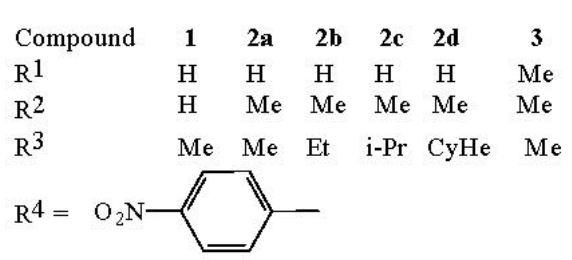

\section{Scheme 1}

In order to distinguish more clearly the two effects we studied molecules where increase in strain was not expected to change the immediate environment of the reacting groups and thus elucidate the action of the gem-dimethyl effect "itself". The cyclization of esters $\mathbf{2 b}$-, $\mathbf{2} \mathbf{c}$-and $\mathbf{2 d -}$ UE, reported in this paper, is just such a case where strain is-introduced by increasing the size of the substituent on 3-N (1-N in the product hydantoin), a position removed by one atom from both the ester and the attacking nitrogen atom. 


\section{Results and Discussion}

\section{a) The pH-rate profiles and mechanisms}

The rates of cyclizations of 3-substituted ethyl 5-(4-nitrophenyl)hydantoates to hydantoins were found rather insensitive to the substitution of methyl for ethyl and even for isopropyl as can be seen on Fig. $1 .^{\S}$ Acid catalysis, $k_{1 H}$ in Table 1 , is increased only by a factor of 2 , while the increase of $k_{\mathrm{OH}}^{b}$ (alkaline catalysis, see below) is even more modest. This contrasts the effect of the same series of 1'-N-substituents in the cyclization of ureidosuccinic acids in $\mathrm{KOH}$ where substitution of Me for cyclohexyl brought about an acceleration of ca. 20 times. ${ }^{5}$ The meager enhancement of cyclization rate of the esters described in this paper could be due to buttressing of 2-methyl by the N-substituent increasing the strain in the sterically more demanding transition state of the esters thus offsetting the GDME. The compound with greatest size of the Nsubstituent, 2d-UE, shows however some considerable changes in the form of the rate profile. Esters $\mathbf{2 b}$-UE and $\mathbf{2 c U E}$ repeat the $\mathrm{pH}$-rate profile of $\mathbf{2 a - U E ~ ( F i g u r e ~ 1 ) ~ c h a r a c t e r i z e d ~ b y ~ t w o ~}$ regions of negatively charged transition state separated by a poorly expressed plateau of charge zero. When Me is replaced by cyclohexyl (Figure 2), the rate profile begins to resemble that of hydantoate 3-UE carrying the maximum of three methyl groups in the chain.

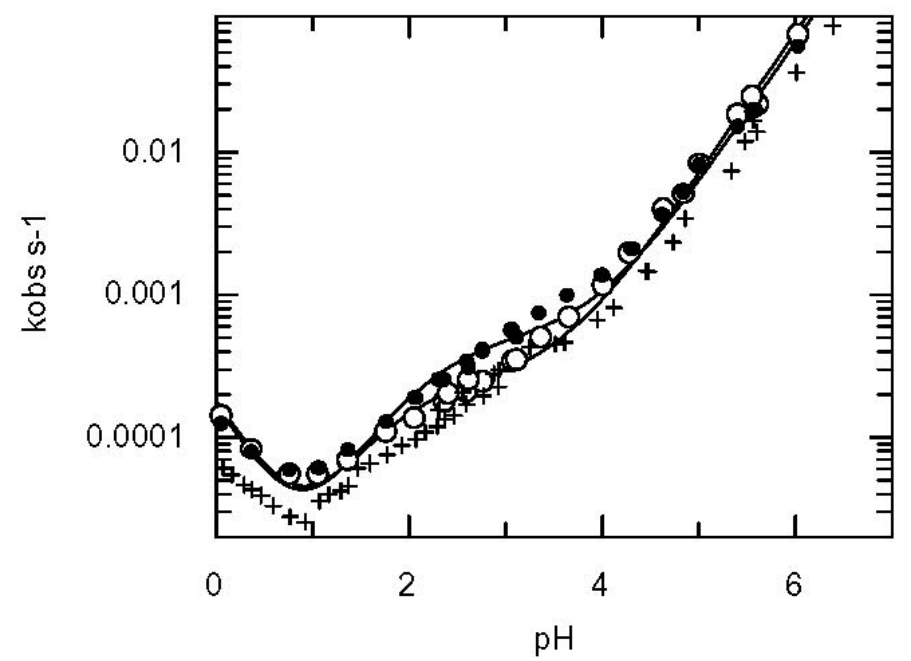

Figure 1 Semilogarithmic plot of the pseudo first order rate constants against $\mathrm{pH}$. 2b-UE -closed circles; $\mathbf{2 c - U E ~ - ~ o p e n ~ c i r c l e s . ~ F o r ~ c o m p a r i s o n ~ x ~ p r e s e n t ~ d a t a ~ f o r ~} \mathbf{2} \mathbf{a}-\mathbf{U E}$. $^{2}$ Lines drawn by means of eqn. (2) and parameters from Table 1. 


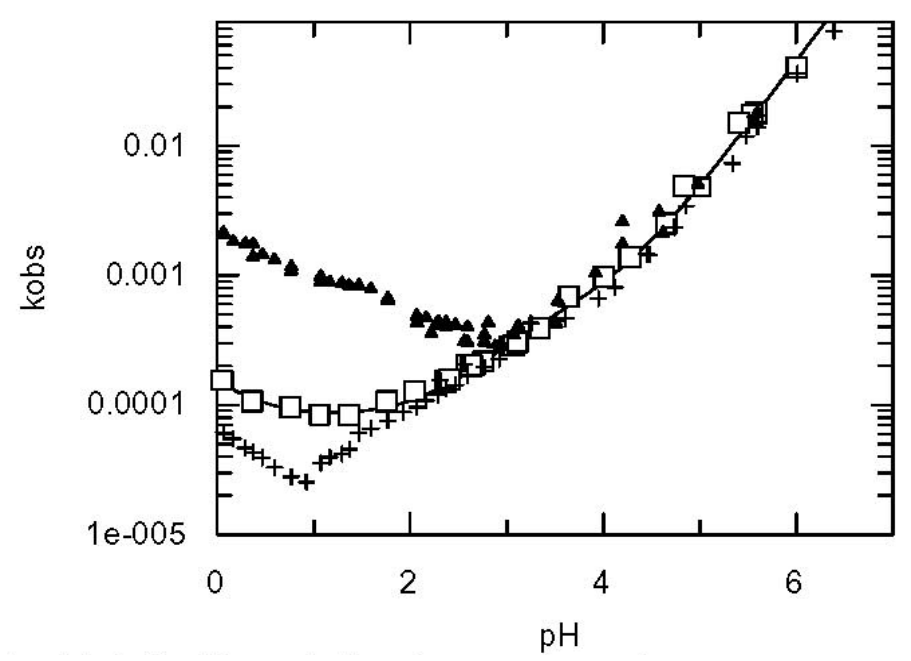

Figure 2 Semilogarithmic plot of the pseudo first order rate constants against $\mathrm{pH}$. 2d-UE open squares; 2a-UE +; 3-UE closed triangles. Line drawn by means of eqn. (4) and parameters for 2d-UE from Table 1.

The new features in the rate profile of $\mathbf{2 d - U E}$ is the appearance of a second "neutral" reaction below $\mathrm{pH} 2$ and closing of the difference in the rates of the two OH'reactions; in ester 3-UE there is actually a single $\mathrm{OH}^{-}$reaction. The behaviour in buffers, to be discussed bellow, is also different.

In order to understand the difference in the shape of the profiles on Fig. 1 and 2 we need to recall the main features of our interpretation of the kinetics of cyclization of methyl-substituted 5-(p-nitrophenyl)-hydantoates. ${ }^{2}$ In the case of 1-UE and $\mathbf{2 a - U E}$ the two ba reactions catalyzed by $\mathrm{OH}^{-}$can be denoted for simplicity as $k_{\mathrm{OH}}^{b}$ at high $\mathrm{pH}$ and $k_{\mathrm{OH}}^{a}$ at low $\mathrm{pH}$. Actually according to the preferred mechanism $k_{O H}^{a}$ results from an inverse proportionality in aH in eqn (1) used to described the $\mathrm{pH}$-rate profile.

$$
k_{o b s}=k_{1 H} a_{H}+\frac{k_{w}^{b}+k_{O H}^{b} a_{O H}}{1+k_{2 H} a_{H}}
$$

Acid catalysis $k_{1 H}$ is treated as a separate reaction while the fractional term of eqn. (1) is derived from the steady-state solution of Scheme $1\left(\mathrm{~A}^{-}=\mathrm{H}_{2} \mathrm{O}\right.$ or $\left.\mathrm{OH}^{-}\right)$, eqn. (2)

$$
k_{o b s}=\frac{\left(k_{f 1 w}+k_{f 1 O H} a_{O H}\right)\left(k_{f 2 w}+k_{f 2 H} a_{H}\right)}{k_{r 1 w}+k_{f 2 w}+\left(k_{r 1 H}+k_{f 2 H}\right) a_{H}}
$$

by implementing the conditions $k_{r l w}<k_{f 2 w}$ for the water-catalyzed partitioning of the intermediate $\mathbf{T}^{-}$and $\mathrm{k}_{\mathrm{r} 1 \mathrm{H}}>\mathrm{k}_{\mathrm{f} 2 \mathrm{H}}$ for the $\mathrm{H}^{+}$-catalyzed partitioning from mechanistic considerations discussed in ref.2 and imposing some limitations on the relative size of the constants of the elementary steps. 


$$
\text { In eqn (1) } k_{O H}^{b}=k_{f 10 H}, k_{w}^{b}=k_{\text {f1W }}, k_{2 H}=k_{p 1 H} / k_{f 2 W} \text { and } k_{O H}^{a}=k_{w}^{b} / k_{2 H} K_{w} \text {. }
$$

Mechanistically, $k_{\mathrm{OH}}^{b}$ is a specific base catalyzed attack of the ureide anion. At low pH the breakdown of $\mathbf{T}^{-}$to reactants catalyzed by $\mathrm{H}^{+}$is faster than that to products, that is formation of $\mathbf{T}$ becomes an equilibrium, and $k_{\mathrm{OH}}^{a}$ presents acid inhibition ${ }^{6}$ of $\mathbf{T}^{-}$. In this $\mathrm{pH}$ region

$$
k_{o b o}=k_{O H}^{a} a_{O H}=\frac{k_{f 1 w} k_{f 2 w}}{k_{P I H} a_{H}}=\frac{K_{T}}{K_{w}} k_{f 2 w} a_{O H}
$$

where $K_{T}$-is the equilibrium constant of the first reaction of Scheme 1 when $\mathrm{A}$ is water and $\mathrm{AH}$ is hydroxonium ion.

As demonstrated on Fig. 1, eqn. (1) gave a fully satisfactory fit to the rate data the newly

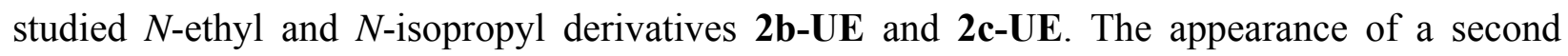
plateau at low $\mathrm{pH}, \mathrm{k}_{w}^{a}$ with the cyclohexyl compound $\mathbf{2 d - U E}$ is not provided for by eqn. (1) because it has been derived on the assumption that in eqn. (2) the condition $k_{f 2 w}>k_{f 2 H} a_{H}$ holds throughout the $\mathrm{pH}$ interval studied. When this restriction is removed eqn. (4) obtains which gives a good fit to the rate data for 2d-UE (Fig. 2):

$$
k_{o b s}=\frac{\left(k_{w}^{b}+k_{O H} a_{O H}\right)\left(1+k_{3 H} a_{H}\right)}{1+k_{2 H} a_{H}}+k_{1 H} a_{H}
$$

where $k_{3 H}=k_{f 2 H} / k_{f 2 w}$ (because $k_{r l w}<k_{f 2 w}$ ). Eqn (4) shows readily that the rate at theplateau at lower $\mathrm{pH}$ then becomes

$$
k_{w}^{a}=k_{w}^{b} k_{3 H} / k_{2 H}=k_{f 1 w} k_{f 2 H} / k_{k p 1 H}=K_{T^{-}} k_{f 2 H}
$$

The rate constants obtained from non-linear regression fits of the rate data to eqns ( 1 and (4)

\begin{tabular}{|c|c|c|c|c|c|}
\hline $\begin{array}{l}\text { Ureido } \\
\text { ester }\end{array}$ & $\begin{array}{l}10^{4} k_{I B} \\
\mathrm{dm}^{3} \mathrm{~mol}^{-1} \mathrm{~s}^{-1}\end{array}$ & $\begin{array}{l}10^{-6} k_{O H}^{b} \\
\mathrm{dm}^{3} \mathrm{~mol}^{-1} \mathrm{~s}^{-1}\end{array}$ & $\begin{array}{l}10^{4} k_{w}^{b} \\
\mathrm{~s}^{-1}\end{array}$ & $\begin{array}{l}10^{-2} k_{2 H} \\
\mathrm{dm}^{3} \mathrm{~mol}^{-1} \mathrm{~s}^{-1}\end{array}$ & $\begin{array}{l}10^{-8} k_{O H}^{a}{ }^{a} \\
\mathrm{dm}^{3} \mathrm{~mol}^{-1} \mathrm{~s}^{-1}\end{array}$ \\
\hline $2 \mathrm{a}-\mathrm{UE}^{\mathrm{b}, \boldsymbol{c}}$ & $0.834 \pm 0.061$ & $3.85 \pm 0.20$ & $2.18 \pm 0.16$ & $1.07 \pm 0.16$ & 2.07 \\
\hline $2 \mathbf{b}-\mathbf{U} \mathbf{E}^{\mathbf{b}}$ & $1.65 \pm 0.19$ & $5.90 \pm 0.38$ & $4.90 \pm 0.50$ & $1.66 \pm 0.34$ & 2.95 \\
\hline $2 \mathrm{c}-\mathrm{UE}^{\mathrm{b}}$ & $1.77 \pm 0.17$ & $6.88 \pm 0.34$ & $2.51 \pm 0.20$ & $0.783 \pm 0.151$ & 3.19 \\
\hline $2 \mathrm{~d}-\mathrm{U} \mathbf{E}^{\mathrm{d}, \mathrm{e}, \mathrm{f}}$ & $0.781 \pm 0.20$ & $4.49 \pm 0.22$ & $5.56^{\mathrm{e}} \pm 1.07$ & $15.7 \pm 5.6$ & 0.353 \\
\hline
\end{tabular}
are listed in Table 1.

Table 1 Rates of cyclization of ethyl 2-methyl-3-alkyl-5-p-nitrophenylhydantoates in water at $25.0^{\circ} \mathrm{C}$ and ionic strength $1 \mathrm{M}(\mathrm{KCl})$ 
Thus according to eqn. (5), the second $\mathrm{pH}$ independent region at lower $\mathrm{pH}$ is due to rate limiting reaction of $\mathbf{T}^{-}$with $\mathrm{H}^{+}$.

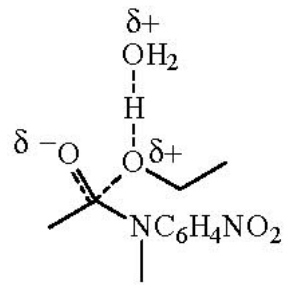

$\mathrm{TS}^{ \pm}$

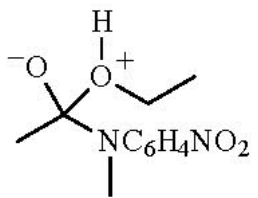

$\mathbf{T}^{ \pm}$

A concerted mechanism corresponding to the transition state, TS, has been preferred for the reaction presented by $k_{\mathrm{OH}}^{a}$ where, however, the acid is a molecule of water. ${ }^{2,3,7 \dagger}$ The protonation by $\mathrm{H}_{3} \mathrm{O}^{+}$leading to $\mathbf{T}^{ \pm}$should be an energetically downhill reaction; so that protonation and breakdown of the tetrahedral intermediate could be consecutive processes.

This analysis affords also a mechanistic interpretation of the rate profile of ester $3 \mathbf{U E}$ studied before $^{2}$ (Fig.2). Two zones of slope zero were identified centered roughly at $\mathrm{pH} 3$ and 1.5, respectively, separated by a slope of minus 1 . Up to the highest $\mathrm{pH}$ studied there is a single basecatalyzed reaction (slope of plus 1) assigned as cleaving of EtO-from 3-T'generally acid catalyzed by water the same as ${k_{O H}^{a}}_{\mathrm{O}}$ in the profiles of esters 2-UE shown on Fig. 1. Thus in the $\mathrm{pH}$-region of transition from slope 1 to $0, \mathbf{T}$ is equilibrating with the reactants, so that the plateau at higher $\mathrm{pH}$ could be either breakdown of the neutral $\mathbf{T}^{\mathbf{0}}$ or, more likely, the kinetically equivalent reaction of $\mathbf{T}^{-}$with $\mathrm{H}^{+}$. The latter preference is now reinforced because eqns. (4) and (5) appear to be reasonable extensions of the behaviour of $\mathbf{T}^{-}$of the 5-p-nitrophenyl esters.

What causes the appearance of the reaction designated as $k_{w}^{a}$.in the case of hydantoates $\mathbf{2 d -}$ UE? In terms of the derivation of eqn. (1) from eqn. (2) this is because below a certain pH (2 with $2 \mathbf{d}-\mathbf{U E}$ ) the inequality $k_{f 2 w}>k_{f 2}{ }_{H} a_{H}$ changes to $k_{f 2 w}<k_{f 2}{ }_{H} a_{H}$ leading to eqn. (4), i.e. the rate constant for acid catalyzed breakdown of $\mathbf{T}$ increases compared to the constant for water catalysis. As discussed in the Introduction under (a) the GDME accelerates the forward steps so that the increase in $\mathrm{k}_{\mathrm{f} 2}$ is wholly expected, what is not immediately obvious is why the increase is less for water catalysis in order for the inequality $k_{f 2 w}>k_{f}{ }_{H} a_{H}$ to change sign in the same $\mathrm{pH}$ region. Actually for the cyclohexyl derivative the value for $k_{2 H}=k_{r 1 H} / k_{f 2 w}$ is substantially greater than that for the remaining compounds while the value for $k_{\mathrm{OH}}^{a}=\frac{K_{\mathrm{T}-}}{K_{w}} k_{\mathrm{f} 2 \mathrm{w}}$ is substantially lower (Table 1). These values indicate that $k_{f 2 w}$ is smaller with the cyclohexyl derivative than with the other ones thus contributing to the appearance of the $k_{w}^{a}$ reaction. ${ }^{\ddagger}$ The appearance of same reaction in the case of 3-UE with an obviously stronger GDME at $\mathrm{pH}$ ca. 3 is on the other hand an indication of the role of a relative increase of $k_{f 2 H}$.

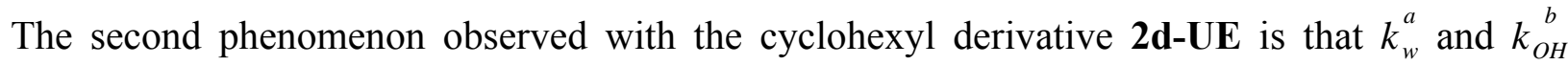
become close in value; the ratio $k_{w}^{a} / k_{O H}^{b}$ is about 50 for compounds $\mathbf{2 a - 2 c - U E}$ but only 8 for $\mathbf{2 d -}$ 


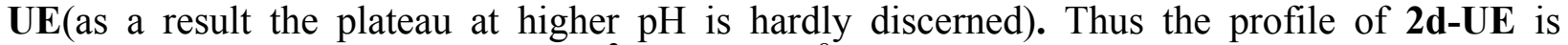
midway between those of ester $\mathbf{3}-\mathbf{U E}^{2}$ and its $\operatorname{acid}^{8}$ with a single $\mathrm{OH}^{-}$catalyzed reaction and the profiles of esters $\mathbf{2 a - c - U E}$ and the acid of $\mathbf{2 a - U E ~ e x h i b i t i n g ~ t w o ~} \mathrm{OH}^{-}$catalyzed reactions. ${ }^{*}$ This can be understood in terms of the conditions necessary to observe two reactions catalyzed by the same species: ${ }^{9}$ there should be two different modes for partitioning of the intermediate caused by differences in the partitioning ratio $k_{f} 2 / k_{r 1}$ (in practice $<1$ or $>1$ ). ${ }^{9}$ And secondly, the intermediate should not be in equilibrium with the reagents at least in one of the modes. Relevant for comparison is the free acid of 3-UE because when the ethyl group in the ester is replaced by hydrogen no steric hindrance to protonation comes into play (paragraph (b) in the Introduction). The mechanism for $\mathrm{OH}^{-}$catalysis with the acid ${ }^{* *}$ could readily be assigned as that of $k_{O H}^{b}$ of the less substituted esters and acids: slow formation of $\mathbf{T}^{-}$by attack of the preliminary ionized $\omega-(\mathrm{p}$ nitrophenyl)ureido group. This mechanism demands $k_{f 2 w} / k_{r 1 w}>1$ as can be readily seen from eqn. (2) for the first step to be rate-determining at high $\mathrm{pH}$. With the less substituted compounds a change of mechanism occurs at lower $\mathrm{pH}$ because $k_{f 2 H} / k_{r 1 H}<1$. The loss of the second reaction at lower $\mathrm{pH}$ in the case of the free acid of 3-UE was attributed to the GDME enhancing the rate in the forward direction and decreasing it in the reverse. This overturns the ratio $k_{f 2 H} / k_{r 1 H}$ to greater than unity so that no change in mechanism can be observed. Apparently the presently studied cyclohexyl ester $\mathbf{2 d}$ is somewhere in between the free acids of $\mathbf{2 a - U E}$ and 3-UE: the two $\mathrm{OH}^{-}$reactions are still discernible but the difference is strongly diminished manifesting the action of the GDME.

\section{(b)Buffer catalysis}

The compounds studied showed buffer catalysis which could be identified as general base catalysis, GBC. The results obtained are summarized in Table 2.

Table 2 Buffer catalysis data for the cyclization of 3-substituted ethyl 5-(4-nitrophenyl)-2methylhydantoates at $25^{\circ} \mathrm{C}$ and ionic strength $1.0 \mathrm{M}$

\begin{tabular}{|c|c|c|c|c|c|c|}
\hline \multirow[t]{2}{*}{ Buffer acid } & \multirow[t]{2}{*}{$\mathrm{pK}_{\mathrm{AH}}^{\mathrm{a}}$} & \multirow[t]{2}{*}{$\begin{array}{l}\text { Conc.range } \\
\mathrm{mol} \mathrm{dm}\end{array}$} & \multirow[t]{2}{*}{$\begin{array}{l}\% \\
\text { base }\end{array}$} & \multicolumn{3}{|c|}{$\begin{array}{c}10^{4} k_{B}, k_{B B} \text { in parenthesis } \\
\mathrm{dm}^{3} \mathrm{~mol}^{-1} \mathrm{~s}^{-1, \mathrm{~b}}\end{array}$} \\
\hline & & & & $2 \mathbf{b}$ & $2 \mathrm{c}$ & 2d \\
\hline \multirow[t]{3}{*}{$\mathrm{H}_{3} \mathrm{~N}^{+} \mathrm{CH}_{2} \mathrm{CO}_{2} \mathrm{H}$} & 2.45 & $0.05-1$ & 30 & $9.11 \pm 2.13$ & $25.2 \pm 3.3$ & $38.8 \pm 0.3 .1$ \\
\hline & & $0.05-0.2$ & 50 & & $(3.42 \pm 0.78)$ & \\
\hline & & $0.05-0.2$ & 70 & & & \\
\hline \multirow[t]{3}{*}{$\mathrm{HCO}_{2} \mathrm{H}$} & 3.57 & $0.01-0.2$ & 30 & $251 \pm 43$ & $203 \pm 28$ & $118 \pm 5$ \\
\hline & & $0.01-0.2$ & 50 & $(6.39 \pm 2.54)$ & $(5.00 \pm 1.94)$ & \\
\hline & & $0.01-0.2$ & 70 & & & \\
\hline \multirow[t]{4}{*}{$\mathrm{CH}_{3} \mathrm{CO}_{2} \mathrm{H}$} & 4.62 & $0.01-0.2$ & 30 & $1190 \pm 160$ & $1090 \pm 150$ & $465 \pm 32$ \\
\hline & & $0.01-0.2$ & 50 & $(6.07 \pm 2.04)$ & $(2.79 \pm 1.68)$ & \\
\hline & & $0.01-0.2$ & 70 & & & \\
\hline & & $0.05-0.2$ & 90 & & & \\
\hline \multirow[t]{3}{*}{$\left(\mathrm{CH}_{3}\right) \mathrm{AsO}_{2} \mathrm{H}$} & 6.19 & $0.01-0.15$ & 10 & $3400 \pm 380$ & $4410 \pm 630$ & $3990 \pm 360$ \\
\hline & & $0.01-0.15$ & 20 & & & \\
\hline & & $0.01-0.15$ & 30 & & & \\
\hline $\mathrm{H}_{2} \mathrm{PO}_{4}^{-}$ & 6.48 & $0.032-0.2$ & 10 & $4860 \pm 120$ & $8890 \pm 120$ & $4140 \pm 1070$ \\
\hline
\end{tabular}


The procedures followed have been described in ref. 2. In cases of uncomplicated GBC plots of $k_{b u f}$ (the slopes of $k_{o b s}$ against buffer concentration at constant buffer ratio) against fraction base are straight lines with slopes equal to $k_{B}$, the rate constant for catalysis

by the general base B. Often upward curvatures in such plots have been observed before in the cyclization of ureido esters and acids and can be due to various reasons. ${ }^{2,3,8}$ This is related to an important difference between the cyclohexyl derivative $\mathbf{2 d - U E}$ and the remaining esters $\mathbf{2 a - c - U E}$ demonstrated on Figure 3. The plot for the former is a straight line in acetate buffers while the rest are curved upward. The slope of the straight line, $k_{B}$ for acetate anion, is $0.046 \pm 0.009$, the same value as that shown on Table 2 which has been obtained by simultaneous fitting of all data by a non-linear regression

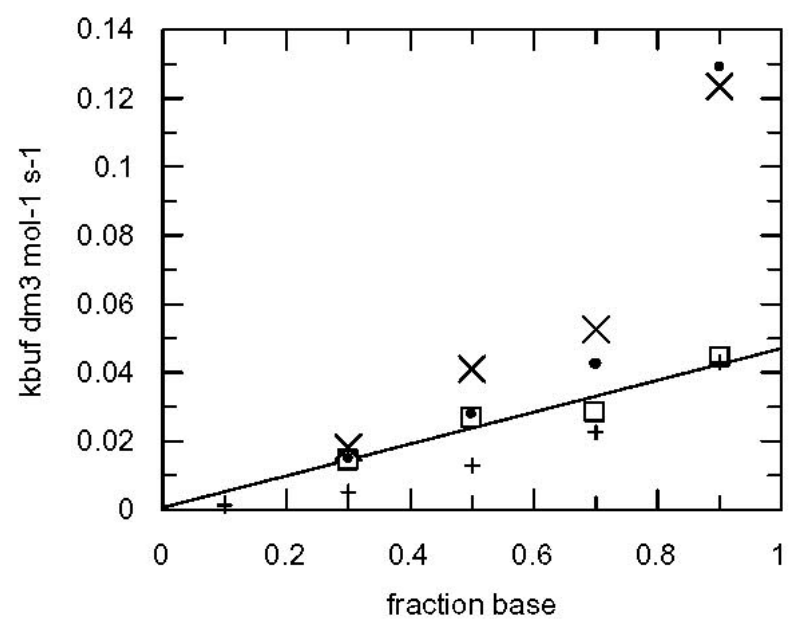

Figure 3. Plots of $k_{b u f}$ against fraction base in acetate buffers for esters $\mathbf{2 a - U E}-+, \mathbf{2} \mathbf{b}-\mathbf{U E}-$ full circles, 2c-UE - X, 2d-UE - open squares. The line presents a linear fit to the data for $\mathbf{2 d - U E \text { . }}$

With esters such as the N-methyl derivative 2a-UE the curvature is due to a change in mechanism. ${ }^{2}$ The GBC has been assigned to $k_{f 1}$ and a transition takes place similar to that $k_{O H}^{b}$ to $k_{w}^{a}$ hen the $\mathrm{pH}$ is lowered i.e. first stage on Scheme 1 becomes a preliminary equilibrium when $k_{r l H} a_{H}>k_{f 2 w^{* *}}$ The mechanism of the GBC reaction changes when the breakdown to reactants catalyzed by the general acid AH becomes faster than the breakdown to products $k_{r 1 \mathrm{AH}}[\mathrm{AH}]>$ $k_{f 2 w}$.

The conditions for the latter transition can be readily appreciated from the above discussion of the rate equations. Above $\mathrm{pH}$ 3-4 the hydantoates cyclize by rate-determining formation of $\mathbf{T}^{-}$. Since the catalysis by the general base has to take place in the rate-determining stage of the main reaction in this region, simple GBC as observed in acetate for $\mathbf{2 d - U E}$ can result from two simultaneous conditions when the terms for catalysis by the general base $\mathrm{A}^{-}$are included in eqn. (1): $k_{f 2 w}>k_{f 2 A H}[\mathrm{AH}]$ in the numerator and $k_{r 1 A H}[\mathrm{AH}]<k_{f 2 w}$ in the denominator. Then eqn. (1) can be expanded as

$$
k_{o b s}=\frac{k_{w}+k_{O H} a_{O H}+k_{B}\left[A^{-}\right]}{1+k_{2 H} a_{H}}+k_{1 H} a_{H}
$$


where $k_{B}=k_{f 1 A^{-}}$of eqn. (2). When at higher $[\mathrm{AH}] k_{r 1 A H}[\mathrm{AH}]>k_{f 2 w}$ we obtain

$$
k_{o b s}=\frac{k_{w}+k_{O H} a_{O H}+k_{B}\left[A^{-}\right]}{1+k_{2 H} a_{H}+k_{B H}[A H]}+k_{1 H} a_{H}
$$

where $k_{B H}=k_{r 1 A H} / k_{f 2 w}$. At sufficiently large [AH] the contribution of buffer catalysis becomes equal to the rate described by eqn. (3), i.e. r.d. breakdown of $\mathbf{T}^{-}$catalyzed by water. In the case of 2d-UE for buffers more acidic than acetate the $k_{B}$ and $k_{B H}$ terms were added to eqn. (4) as above. The collected $k_{o b s}$ data for each buffer were fitted both to the equation with and without a $k B H$ term in the denominator and the better fits are given in Table 2.

Why does the $k_{B H}$ term disappear in the case of the cyclohexyl derivative $2 \mathbf{d}-\mathbf{U E}$ in acetate and more acidic buffers? This is another phenomenon in line with the GDME upon partitioning of tetrahedral intermediates. The $k_{B H}$ term being equal to $k_{r 1 A H} / k_{f 2 w}$ should decrease with the GDME because the latter decreases $k_{r 1}$ and increases $k_{f 2}$. Apparently, $k_{B H}$ with $2 \mathbf{d}-\mathbf{U E}$ is too small to cause a shift in the rate determining step.

The GBC catalysis has been assigned ${ }^{2}$ to removal of the $\omega-\mathrm{N}-\mathrm{H}$ proton concerted with the formation of $\mathbf{T}^{-}$. Fig. 4 illustrates the similarity of the Brønsted plots of compounds

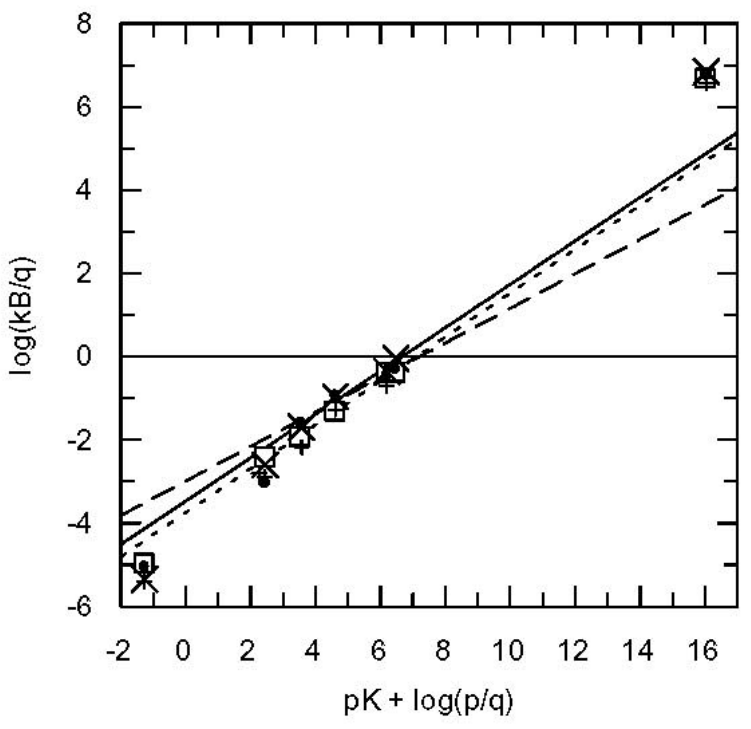

Figure 3 Brønsted plots of rate constants for GBC ( $p$ and $q$ are statistical corrections for number of protons and basic sites respectively). Cyclization of $\mathbf{2 a - U E ~ - ~ + , ~} \mathbf{2} \mathbf{b}-\mathbf{U E}-$ full circles, $\mathbf{2 c - U E}-$ $\mathrm{X}$, and $\mathbf{2 d - U E ~ - ~ o p e n ~ s q u a r e s . ~ L i n e s ~ a r e ~ l i n e a r ~ f i t s ~ t o ~} 4$ points from formate to phosphate for $\mathbf{2 b -}$ $\mathbf{U E}$ (dashes) and 2c-UE (unbroken line), and fit to 5 points from glycine to phosphate for $\mathbf{2 d - U E}$ (dots)

$\mathbf{2 b}-\mathbf{2 d - U E}$ to that of the $N$-methyl derivative $\mathbf{2 a - U E}$ studied before ${ }^{2}$ The points for catalysis by water and hydroxide deviate and were excluded in the calculation of the Brønsted $\beta$-values listed 
on Table 3. For compounds 1-UE and 2-UE these are around $0.50 \pm 0.08$. All this adds further credence on the above interpretations based on the presumption that the same mechanism operates. $*$.

Table 3. Brønsted $\beta$-values for general base catalysis of the cyclization of ethyl pnitrophenylhydantoates

\begin{tabular}{|c|c|c|c|}
\hline Compound & $\beta$ & \# of points & $\mathrm{r}$ \\
\hline 1-UE & $0.50 \mathrm{a}$ & 5 & 0.9559 \\
\hline 2a-UE & $0.58 \mathrm{a}$ & 5 & 0.9866 \\
\hline 2b-UE & 0.42 & $4 a$ & 0.9834 \\
\hline 2c-UE & 0.525 & 4 & 0.9902 \\
\hline 2d-UE & 0.53 & 5 & 0.9975 \\
\hline
\end{tabular}

${ }^{\text {a }}$ From ref. 2.

(c) Steric strain

As pointed out already, unexpectedly no significant rate increase of cyclization was observed with increasing the size of the 1'-N-substituent. There is little doubt that the source of the GDME - the strain in the open-chained esters increases in the series $\mathbf{2 a - U E}-\mathbf{2 d - U E}$. One albeit indirect indication are the NMR signals for $\mathrm{CH}_{2}$ of the ester ethyl groups (Table 5). At the resolution used diastereotopicity showed up only with the isopropyl and cyclohexyl derivatives indicating conformational restriction. In order to check the hypothesis that the strain increases to a similar degree in the transition state molecular mechanics and semi empirical calculations were carried out on the esters and on the tetrahedral intermediates $\mathbf{T}^{-}$(Scheme 1). The molecular mechanics modeling was carried out utilizing the MM3 force field. ${ }^{14}$ A partial atomic charge -0.6 was placed on the Oatom of the tetrahedral intermediates as determined from AM1 computations. An effective dielectric constant 2.0 was used for the estimation of the electrostatic interactions. MOPAC 93.00 was used for the semiempirical molecular orbital calculations. ${ }^{15}$

Examination of the structural parameters (torsional and bond angles) obtained by means of MM3 could not pin-point to any drastic changes brought about by the Ncyclohexyl group. One significant feature is however the marked decreased puckering of the ring in $\mathbf{T}^{-}$of $\mathbf{2 d - U E}$ accompanied by broadening of the endo bond angles. Apparently the ring is in some way compressed in spite of being equatorial in the cyclohexane ring according to the proton couplings in the NMR. The strain energies cannot be compared directly because the compounds carry different number of atoms. This is circumvented by comparing the double differences:

$$
\begin{gathered}
\Delta \Delta \text { Strain }^{\prime}=\Delta \text { Strain }^{-}--\Delta \text { Strain }_{\mathbf{H y d}} \\
\Delta \text { Strain }=\operatorname{Strain}(\mathbf{n})-\operatorname{Strain}(\mathbf{1}), \mathbf{n}=\mathbf{1}, \mathbf{2 a}, \mathbf{2 d}, \mathbf{3}
\end{gathered}
$$


Table 4. MM3 strain energies ${ }^{\mathrm{a}}$

\begin{tabular}{lll}
\hline Compound & $\Delta$ StrainT $-\Delta$ StrainHyd & $\Delta \Delta$ Strain \\
\hline $\mathbf{1}$ & $(6.7-6.7)-(19.9-19.9)=0.0-0.0$ & $=0.0$ \\
2a & $(9.8-6.7)-(22.9-19.9)=3.1-3.0$ & $=0.1$ \\
2d & $(13.0-6.7)-(26.4-19.9)=6.3-6.5$ & $=0.2$ \\
3 & $(11.6-6.7)-(27.7-19.9)=4.9-7.8$ & $=2.9$ \\
\hline
\end{tabular}

${ }^{a}$ Details from the calculations are available on request from the authors.

The data in the second column of Table 4 nicely confirm the assumption that the practical absence of rate increase upon enlarging the 3-N-substituent in the hydantoates is due to parallel increase in the cyclic transition state. In compound 3-UE which shows a normal GDME (Fig. 2) the double difference is decreased in the absolute sense because of the larger strain in the open chain as demanded by theory.

\section{Conclusions}

The behaviour of ethyl 3-cyclohexyl-2-methylhydantoate, 2d-UE, compared to that of the esters with smaller substituents in position 3 is characterizes by the appearance of a new reaction, decreased difference in the rates of the two $\mathrm{OH}^{-}$reactions and simple versus complex GBC. All these features agree with the concept that the GDME tends to shift the transition state to an earlier step of the cyclization reaction.

\section{Experimental Section}

General Procedures. The melting points were measured in capillaries, the IR spectra in $\mathrm{CHCl}_{3}$ on a Specord IR 75 instrument and the ${ }^{1} \mathrm{H}$ NMR spectra on a Bruker WM-250 instrument. ${ }^{1} \mathrm{H}-$ NMR signals were referenced TMS and coupling constants are given in $\mathrm{Hz}$ and without sign. Mass spectra EI on a JEOL JMS-D 300 spectrometer. pHs were measured with a Radiometer $\mathrm{pH}$ M 84 Research pH-meter using a GK $2401 \mathrm{C}$ electrode. Materials. Inorganic reagents and buffer components were of analytical grade and used without further purification. Potassium hydroxide and buffer solutions were prepared with $\mathrm{CO}_{2}$-free distilled water.

3-Substituted ethyl 2-methyl-5-(4-nitrophenyl)hydantoates 2b-,2c-,2d-UA. We prepared the starting $N$-substituted alanines ${ }^{11,12}$ using the procedure of Lawson and Morley ${ }^{12}$ from 2bromopropionic acid and the respective amine. After removing carefully all traces of excess amine in vacuo, the free amino acids were obtained in pure form by passing through a column packed with ion-exchange resin Amberlite IR-120 in $\mathrm{H}^{+}$-form and eluting with $2 \mathrm{~N}$ ammonia. The solution of the amino acid was evaporated to dryness. Recrystallization from ethanol to gave products with literature m.p. in $76-93 \%$ yields. Standard esterification ${ }^{13}$ with $\mathrm{HCl} / \mathrm{EtOH}$ and 
vacuum distillation afforded the amino esters in high yields. The ethyl hydantoates $\mathbf{2 b - 2 d - U E ~}$ were prepared from the freshly distilled amino esters and p-nitrophenyl isocyanate according to the procedure described in ref. 2 and used without further purification due to their instability.

1-Substituted-5-methyl-3-(4-nitrophenyl)hydantoins $2 \mathrm{~b}-, 2 \mathrm{c}-, \mathbf{2 d}-\mathrm{Hyd}$. The product hydantoins 2b-2d-Hyd were prepared from the respective amino acids and p-nitrophenyl isocyanate as detailed in ref. 2. The compounds were recrystallized from ethanol-water 2:1.

The properties of the compounds synthesized are summarized in Tables 5 and 6.

Table 5. Melting-points, yields of syntheses and elemental analyses of ethyl 3-substituted-2methyl-5-(4-p-nitropheny)hydantoates 2-UE and 1-substituted-5-methyl-3-(4nitrophenyl)hydantoins 2-Hyd

\begin{tabular}{|c|c|c|c|c|c|c|c|c|}
\hline \multirow{2}{*}{ Compound } & \multirow{2}{*}{$\mathrm{mp} .{ }^{\circ} \mathrm{C}$} & \multirow{2}{*}{$\begin{array}{c}\text { Yield } \\
\%\end{array}$} & \multirow{2}{*}{${ }^{v} \mathrm{CO} \mathrm{cm}-1$} & \multirow{2}{*}{$\begin{array}{l}\text { Formula } \\
\text { (MW) }\end{array}$} & \multirow{2}{*}{$\begin{array}{l}\mathrm{M}+ \\
\mathrm{m} / \mathrm{z} \\
\mathrm{C}\end{array}$} & \multicolumn{3}{|c|}{ Calculated/found (\%) } \\
\hline & & & & & & & $\mathrm{H}$ & $\mathrm{N}$ \\
\hline \multirow[t]{2}{*}{ 2b-UE } & $125-126$ & 84 & 1726 & $\mathrm{C} 14 \mathrm{H} 19 \mathrm{~N} 3 \mathrm{O} 5$ & 309 & & & \\
\hline & & & 1675 & $(309.3)$ & & & & \\
\hline \multirow[t]{2}{*}{$2 c-U E$} & $108-109$ & 91 & 1724 & $\mathrm{C} 15 \mathrm{H} 21 \mathrm{~N} 3 \mathrm{O} 5$ & 323 & & & \\
\hline & & & 1674 & $(323.3)$ & & & & \\
\hline \multirow[t]{2}{*}{ 2d-UE } & $118-120$ & 90 & 1726 & $\mathrm{C} 18 \mathrm{H} 25 \mathrm{~N} 3 \mathrm{O} 5$ & 363 & & & \\
\hline & & & 1673 & $(363.2)$ & & & & \\
\hline \multirow[t]{2}{*}{ 2b-Hyd } & $125-126$ & 74 & 1775 & $\mathrm{C} 12 \mathrm{H} 13 \mathrm{~N} 3 \mathrm{O} 4$ & & 54.75 & 4.98 & 15.92 \\
\hline & & & 1720 & (263) & & 54.44 & 4.82 & 15.72 \\
\hline \multirow[t]{2}{*}{ 2c-Hyd } & $111-112$ & 65 & 1770 & $\mathrm{C} 13 \mathrm{H} 15 \mathrm{~N} 3 \mathrm{O} 4$ & & 56.31 & 5.45 & 15.15 \\
\hline & & & 1715 & (267) & & 56.43 & 5.28 & 15.39 \\
\hline \multirow[t]{2}{*}{ 2d-Hyd } & $121-122$ & 52 & 1770 & $\mathrm{C} 16 \mathrm{H} 19 \mathrm{~N} 3 \mathrm{O} 4$ & & 60.56 & 6.03 & 13.24 \\
\hline & & & 1722 & $(345)$ & & 61.04 & 5.86 & 13.18 \\
\hline
\end{tabular}

${ }^{\text {a }}$ Calculated values in first row, found values in second row.

Table 6. ${ }^{1} \mathrm{H}$ NMR spectra of ureido esters and hydantoins in $\mathrm{CDCl}_{3}$, $\delta$ in ppm from TMS, couplings $\mathrm{s}^{\mathrm{a}}$ in $\mathrm{Hz}$

\begin{tabular}{|c|c|c|c|c|c|c|c|}
\hline Compound & $2-\mathrm{H}$ & $2-\mathrm{CH}_{3}$ & $\mathrm{~N}-\mathrm{R}$ & & $\mathrm{NH}$ & $o-\mathrm{H}^{\mathrm{b}}$ & $m-\mathrm{H}^{\mathrm{b}}$ \\
\hline \multirow[t]{2}{*}{$2 b-\mathbf{U E}^{\mathrm{c}}$} & $\begin{array}{l}4.622 q \\
(7.3)\end{array}$ & $\begin{array}{l}1.543 \mathrm{~d} \\
(7.3)\end{array}$ & $\mathrm{CH}_{2}$ & $\mathrm{CH}_{3}$ & $7.391 \mathrm{~s}$ & $\begin{array}{l}7.555 \mathrm{~d} \\
(9.2)\end{array}$ & $\begin{array}{l}8.186 \mathrm{~d} \\
(9.2)\end{array}$ \\
\hline & & & $3.450 \mathrm{~m}^{\mathrm{d}}$ & $\begin{array}{l}1.299 \mathrm{t} \\
(7.2)\end{array}$ & & & \\
\hline 2b-Hyd & $\begin{array}{l}4.180 \mathrm{q} \\
(7.0)\end{array}$ & $\begin{array}{l}1.571 \mathrm{~d} \\
(7.0)\end{array}$ & $\begin{array}{l}3.312^{\mathrm{e}} \\
(7.2,14.1) \\
3.900^{\mathrm{e}}\end{array}$ & $\begin{array}{l}1.272 \\
(7.2)\end{array}$ & & $\begin{array}{l}7.783 d \\
(9.2)\end{array}$ & $\begin{array}{l}8.312 \mathrm{~d} \\
(9.2)\end{array}$ \\
\hline
\end{tabular}


$(7.2,14.1)$

\begin{tabular}{|c|c|c|c|c|c|c|c|}
\hline $2 \mathbf{c}-\mathbf{U} \mathbf{E}^{\mathrm{f}}$ & $\begin{array}{l}4.066 \mathrm{q} \\
(7.3)\end{array}$ & $\begin{array}{l}1.585 \mathrm{~d} \\
(7.3)\end{array}$ & $\begin{array}{l}\mathrm{CH} \\
4.445^{\mathrm{g}} \\
(6.8)\end{array}$ & $\begin{array}{l}\mathrm{CH}_{3} \\
1.235 \mathrm{~d} \\
(6.8) \\
1.251 \mathrm{~d} \\
(6.7)\end{array}$ & $8.478 \mathrm{~s}$ & $\begin{array}{l}7.544 \mathrm{~d} \\
(9.2)\end{array}$ & $\begin{array}{l}8.161 \mathrm{~d} \\
(9.2)\end{array}$ \\
\hline 2c-Hyd & $\begin{array}{l}4.175 q \\
(6.9)\end{array}$ & $\begin{array}{l}1.612 d \\
(6.9)\end{array}$ & $\begin{array}{l}4.230^{\mathrm{g}} \\
(6.9)\end{array}$ & $\begin{array}{l}1.390 \mathrm{~d} \\
(6.9) \\
1.401 \mathrm{~d} \\
(6.9)\end{array}$ & & $\begin{array}{l}7.783 \\
(9.2)\end{array}$ & $\begin{array}{l}8.308 \mathrm{~d} \\
(9.2)\end{array}$ \\
\hline 2d-UE ${ }^{\mathrm{h}}$ & $\begin{array}{l}4.092 q \\
(7.3)\end{array}$ & $\begin{array}{l}1.571 \mathrm{~d} \\
(7.3)\end{array}$ & $\begin{array}{l}\mathrm{CH}\left(\mathrm{C}_{5} \mathrm{H}_{10}\right) \\
3.994^{\mathrm{i}}\end{array}$ & $\begin{array}{l}\mathrm{C}_{5} \mathrm{H}_{10} \\
1.08-1.88\end{array}$ & $8.475 \mathrm{~s}$ & $\begin{array}{l}7.545 \mathrm{~d} \\
(9.2)\end{array}$ & $\begin{array}{l}8.161 \mathrm{~d} \\
(9.2)\end{array}$ \\
\hline 2d-Hyd & $\begin{array}{l}4.174 q \\
(6.9)\end{array}$ & $\begin{array}{l}1.613 \mathrm{~d} \\
(6.9)\end{array}$ & $\begin{array}{l}3.792 \mathrm{tt} \\
(12.0,3.9)\end{array}$ & $1.10-2.00$ & & $\begin{array}{l}7.780 \mathrm{~d} \\
(9.2)\end{array}$ & $\begin{array}{l}8.312 \mathrm{~d} \\
(9.2)\end{array}$ \\
\hline
\end{tabular}

${ }^{\mathrm{a}}$ In parenthesis. ${ }^{\mathrm{b}}$ Signals show additional fine structure. ${ }^{\mathrm{c}} \mathrm{OCH}_{2} 4.231 \mathrm{q}(7.1) ; \mathrm{OCH}_{2} \mathrm{CH}_{3} 1.303$ $\mathrm{t}(7.1) .{ }^{\mathrm{d}}$ Due to small chemical shift difference of the two diastereotopic protons. ${ }^{\mathrm{e}}$ Sextet. ${ }^{\mathrm{f}} \mathrm{OCH}_{2}$ $4.262 \mathrm{~m}$ due to different chemical shifts of methylene protons, $\mathrm{OCH}_{2} \mathrm{CH}_{3} 1.3093 \mathrm{t}$ (7.1). ${ }^{\mathrm{g}}$ Septet. ${ }^{\text {h }} \mathrm{OCH}_{2} 4.267 \mathrm{~m}$ due to different chemical shifts of methylene protons, $\mathrm{OCH}_{2} \mathrm{CH}_{3}$ 1.306t (7.1). I Poorly resolved triplet of triplets $(11,3)$.

Product analysis. The cyclizations of the ethyl hydantoates studied in this paper proceeded quantitatively to the corresponding hydantoins. Good isosbestic points were obtained for all three compounds studied and the end-point absorbances for the kinetic runs were identical within experimental error with the absorbances of model solutions of the respective hydantoins.

Kinetic measurements.Rate constants were determined at $(25.0 \pm 0.01){ }^{\circ} \mathrm{C}$ under pseudo-first order conditions in the thermostatted cell compartment of a Unicam SP-800 or Carl Zeiss Jena UV VIS spectrophotometer. The rates of cyclization of the substituted esters were followed by monitoring the decrease of the absorbance at $330 \mathrm{~nm}$ due to the 4-nitrophenylureido group. Reactions were initiated by injecting $20 \mu \mathrm{L}$ of $1 \times 10^{-2} \mathrm{M}$ stock solutions of the substrates in dry THF into $2.7 \mathrm{~cm}^{3}$ preheated buffer solution. Ionic strength was maintained constant $(1.0 \mathrm{M})$ with $\mathrm{KCl}$. . Pseudo-first-order rate constants ${ }^{\S}, \mathrm{k}_{\mathrm{obs}}$, were obtained by nonlinear-regression curve fitting to the equation $A_{t}=A_{o} e^{- \text {kobst }}+A_{\times}$by means of the GRAFIT program where $A_{t}, A_{o}$, and $A_{\times}$are the absorbances at times $t$, zero, and infinity, respectively.

$\mathrm{pH}$-Values were measured at the end of each kinetic run. No interference from ester hydrolysis was detected as judged by the good linear plots $(r>0.999)$ of $\ln \left(A_{t}-A_{\infty}\right)$ against time obtained over three half-lives.

The individual rate constants were obtained also by means nonlinear regression fitting to the respective rate equations by means of the GRAFIT program. 


\section{Acknowledgements}

Helpful discussions with Dr. B. I. Blagoeva are gratefully acknowledged.

\section{References}

1. (a) Ingold, C. K. J. Chem. Soc. 1921, 119, 305. (b) Ingold, C. K.; Sako, S.; Thorpe J. F. J. Chem. Soc. 1922, 1117. (c) Allinger, N. L.; Zalkow, V. J. Org. Chem. 1960, 25, 701. (d) Blagoeva, I. B.; Kurtev, B. J.; Pojarlieff, I. G. J. Chem. Soc., Perkin Trans. 2 1979, 1115. (e) Kirby, A. J. Adv. Phys. Org. Chem. 1980, 17, 183. (f) Valter, R. E. Usp. Khim. 1982, 51, 1374. (g) Mandolini, L. Adv. Phys. Org. Chem. 1986, 22, 17. (h) Verevkin, S. P.; Kümmerlin, M.; Beckhaus, H.-D.; Galli, C.; Rüchardt, C. Eur. J. Org. Chem. 1998, 579.

2. Blagoeva, I. B.; Kirby, A. J.; Koedjikov, A. H.; Pojarlieff, I. G. Can. J. Chem. 1999, 77, 849.

3. Atay, E.; Blagoeva, I. B.; Kirby, A. J.; Pojarlieff, I. G. J. Chem. Soc., Perkin Trans. 2 1998, 2289.

4. Koedjikov, A. H.; Blagoeva, I. B.; Pojarlieff, I. G.; Kirby, A. J. J. Chem. Soc., Perkin Trans. 2. 1996, 2479.

5. Kaneti, J.; Kirby, A. J.; Koedjikov, A. H.; Pojarlieff, I. G. unpublished results.

6. Davies K.J.; Page, M.I. J. Chem. Soc., Chem. Commun. 1990, 1448.

7. Jencks, W.P. Acc. Chem. Res. 1976, 9, 425.

8. Blagoeva, I. B.; Kirby, A. J.; Kochiyashki, I. I.; Koedjikov, A. H.; Pojarlieff, I. G.; Toteva, M. M. J. Chem. Soc. Perkin Trans. 2, 2000, 1953

9. Detar, D. F.; J. Am. Chem. Soc. 1982, 104, 7205.

10. Blagoeva, I.B. J. Chem. Soc., Perkin Trans. 2 1987, 127.

11. Skita, A.; Wulff, C. Ann. 1927.

12. Lawson, A. C.; Morley, M. V. J. Chem. Soc. 1955, 453, 190.

13. Leonard, N. J.; Rnyle, W. V. J. Am. Chem. Soc. 1949, 71, 3094.

14. (a) Allinger, N. L.; Yuh, Y. H.; Lii, J. H. J. Am. Chem. Soc. 1989, 111, 8551. (b) Lii, J. H.; Allinger, N. L. J. Am. Chem. Soc. 1989, 111,8566. (c) Lii, J. H.; Allinger, N. L. J. Am. Chem. Soc. 1989, 111, 8576. (d) MM3 (92), Technical Utility Corporation, 235 Glen Village Court, Powell, OH 43065.

15. Stewart, J. J. P. MOPAC 93.00, Fujitsu Ltd., Tokyo, Japan, 1993. 